\title{
Heat of Fluorination of Cobaltous Fluoride, and the Heats of Reaction of Cobaltic Fluoride with Hydrogen and with Bis(trifluoromethyl)benzene $\left(a, a, a, a^{\prime}, a^{\prime}, a^{\prime}-\right.$ Hexafluoroxylene)
}

\author{
By Ralph S. Jessup, F. G. Brickwedde, and Martin T. Wechsler ${ }^{1}$ \\ Calorimetric measurements of the heats of the following reactions have been made, with \\ the results indicated: \\ (1) $2 \mathrm{CoF}_{2}(\mathrm{c})+\mathrm{F}_{2}(\mathrm{~g})=2 \mathrm{CoF}_{3}(\mathrm{c}), \Delta H\left(250^{\circ} \mathrm{C}\right)=-56.1 \pm 2.0 \mathrm{kcal}$; \\ (2) $\mathrm{C}_{6} \mathrm{H}_{4}\left(\mathrm{CF}_{3}\right)_{2}(\mathrm{~g})+14 \mathrm{CoF}_{3}(\mathrm{c})=\mathrm{C}_{6} \mathrm{~F}_{10}\left(\mathrm{CF}_{3}\right)_{2}(\mathrm{~g})+14 \mathrm{CoF}_{2}(\mathrm{c})+4 \mathrm{HF}(\mathrm{g})$, \\ $\Delta H\left(335^{\circ} \mathrm{C}\right)=-409 \pm 20(?) \mathrm{kcal}$; \\ (3) $2 \mathrm{CoF}_{3}(\mathrm{c})+\mathrm{H}_{2}(\mathrm{~g})=2 \mathrm{CoF}_{2}(\mathrm{c})+2 \mathrm{HF}(\mathrm{g}), \Delta H\left(335^{\circ} \mathrm{C}\right)=-74 \pm 4 \mathrm{kcal}$. \\ The values given for the heats of reactions 1 and 3 are consistent, within the assigned \\ probable errors, with available data on the heat of formation of hydrogen fluoride. Reac- \\ tion 2 was accompanied by unknown side reactions, and the value reported represents the \\ heat of the reactions that actually took place in the calorimeter per 14 moles of $\mathrm{CoF}_{3}$ reduced. \\ The error in the value given for the heat of this reaction, as written, may therefore be con- \\ siderably greater than that indicated by the assigned probable error.
}

\section{Introduction}

The work described in this paper was done during 1943 and 1944 at the request of the Manhattan District of the U. S. Army Corps of Engineers. At the time the work was done the need for data of moderate accuracy was urgent. For this reason, very little time could be devoted to development of apparatus, and the purity of the materials supplied for the measurements was not investigated. The results obtained are, therefore, not of high accuracy. It is believed, however, that they are of sufficient interest to justify their publication.

We were requested to measure the heats of the following two reactions:

$$
2 \mathrm{CoF}_{2}(\mathrm{c})+\mathrm{F}_{2}(\mathrm{~g})=2 \mathrm{CoF}_{3}(\mathrm{c})
$$

and

$$
\begin{gathered}
\mathrm{C}_{6} \mathrm{H}_{4}\left(\mathrm{CF}_{3}\right)_{2}(\mathrm{~g})+14 \mathrm{CoF}_{3}(\mathrm{c})=\mathrm{C}_{6} \mathrm{~F}_{10}\left(\mathrm{CF}_{3}\right)_{2}(\mathrm{~g})+ \\
14 \mathrm{CoF}_{2}(\mathrm{c})+4 \mathrm{HF}(\mathrm{g}) .
\end{gathered}
$$

${ }_{1}$ Present address University of Michigan, Ann Arbor, Mich.
The heat of the first reaction was determined at about $250^{\circ} \mathrm{C}$ and that of the second at about $335^{\circ}$ C. According to information available to us, the reactions proceed too slowly at lower temperatures to permit accurate determination of the heat evolved, and at temperatures above $335^{\circ} \mathrm{C}$, products other than $\mathrm{C}_{6} \mathrm{~F}_{10}\left(\mathrm{CF}_{3}\right)_{2}$ are formed in considerable amounts in the reaction of $\mathrm{C}_{6} \mathrm{H}_{4}\left(\mathrm{CF}_{3}\right)_{2}$ with $\mathrm{CoF}_{3}$. We were informed that, at $335^{\circ} \mathrm{C}$, reaction 2 proceeded as indicated and was reasonably free from side reactions.

The value obtained for the heat of reaction 1 , namely, $\Delta H=-56.1 \mathrm{kcal}$ at $250^{\circ} \mathrm{C}$, differed so greatly from the value, $\Delta H=-159.2 \mathrm{kcal}$; previously reported by Jellinek and Koop ${ }^{2}$ for this reaction, that it was thought desirable to check the value obtained in the present investigation. This was done by determining the heat of the reaction,

$$
2 \mathrm{CoF}_{3}(\mathrm{c})+\mathrm{H}_{2}(\mathrm{~g})=2 \mathrm{CoF}_{2}(\mathrm{c})+2 \mathrm{HF}(\mathrm{g}),
$$

K. Jellinek and R. Koop, Z. physik. Chem. A145, 305 (1929). 
and comparing the experimental result with a value calculated from our value for the heat of reaction 1 , and a value reported in the literature for the heat of the reaction,

$$
\frac{1}{2} \mathrm{H}_{2}(\mathrm{~g})+\frac{1}{2} \mathrm{~F}_{2}(\mathrm{~g})=\mathrm{HF}(\mathrm{g}) .
$$

The heat of reaction 3 was measured at about $335^{\circ} \mathrm{C}$ with the same apparatus used for reactions 1 and 2 .

\section{Method, Apparatus, and Materials}

The method consisted in comparing the temperature changes produced in a calorimetric system by measured amounts of chemical reaction and of electric energy.

Figure 1 is a schematic diagram of the apparatus. The calorimeter consisted of the Dewar flask, Q, containing liquid Aroclor No. 5460 in which was immersed the reaction vessel, $N$. A heating coil of bare nichrome wire for supplying electric energy was wound on the insulated supports, $L$, and was provided with potential leads for measuring the impressed voltage. By means of the screw propeller, $K$, the bath liquid was driven downward past the heater; through the tube, $J$; through openings in the steel support, $P$; upward between the tube, $J$, and the wall of the Dewar flask; and back into the tube, $J$, through holes located just above the propeller.

In order to reduce heat loss from the Dewar flask, it was immersed in an unstirred liquid Aroclor bath in the iron cylinder, $R$. This outer bath was heated by a 660 -watt contact heater, $U$, at the bottom and by two 2,000-watt immersion heaters (not shown in fig. 1), which were coiled inside and against the iron cylinder, $R$. During a calorimetric measurement the outer bath was maintained manually at an approximately constant temperature somewhat higher than that of the calorimeter. Loss of heat from the top of the calorimeter was reduced by means of the jacket cover, $G$, of the type described by White ${ }^{3}$ consisting of two sheets of copper separated by the asbestos board, $H$, and bent down at the edges so as to dip into the liquid in the outer bath, $R$. In spite of the precautions taken, the heat loss

\footnotetext{
${ }^{3}$ W. P. White, J. Am. Chem. Soc. 48, 1149 (1926); The Modern Calorim eter p. 152 (Reinhold Publishing Corporation, New York, N. Y., 1928).
}

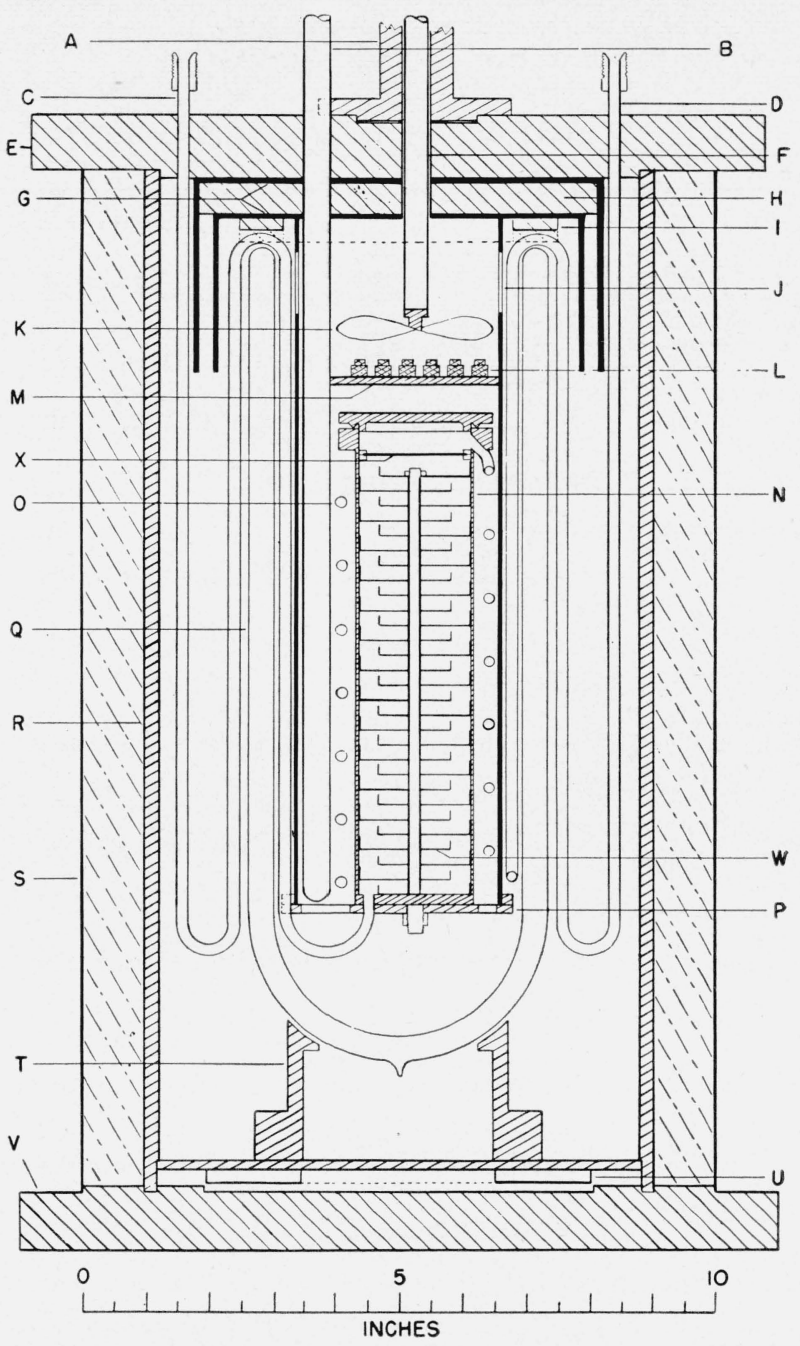

FigURE 1. Diagram of calorimeter.

$A$, Steel support for stirring motor and shield for propeller shaft; $B$, platinum resistance thermometer; $C$, inlet tube leading through outer bath to reaction vessel in calorimeter; $D$, exit tube (continuation of tube, $O$ ); $E$, transite board; $F$, propeller shaft of monel metal tubing; $G$, copper shields; $H$, transite board separating shields; $I$, transite ring between top of Dewar flask and copper shield (has slots to permit passage of inlet and outlet tubes); $J$, copper baffle tube; $K$, propeller; $L$, heater supports; $M$, steel ring holding heater supports; $N$, reaction vessel; $O$, coiled outlet tube from reaction vessel; $P$, steel support for reaction vessel (permits passage of bath liquid out of baffle tube, $J) ; R$, steel container for outer bath; $S$, galvanized iron outer case (the space between $R$ and $S$ was filled with rock wool for insulation); $T$, support for Dewar flask; $U$, ring heater; $V$, transite base; $W$, trays for cobalt fluoride powder; $X$, nickel gauze (600-mesh).

from the calorimeter was relatively large. This is believed to have been due principally to evaporation of the Aroclor.

The outer bath was insulated by a 1-inch layer of rock wool around the cylindrical wall, and by the asbestos boards, $E$ and $V$, at the top and bottom, respectively. The jacket cover, $G$, and 

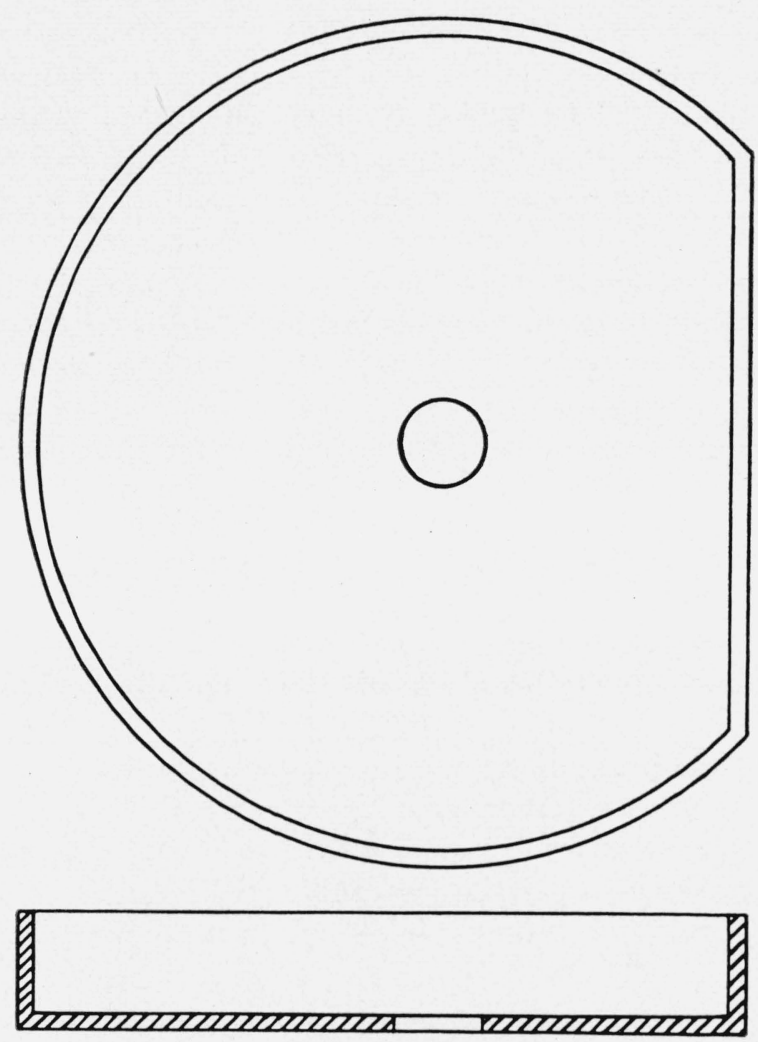

Figure 2.-Tray for holding cobalt fluoride powder in reaction vessel.

the tube, $J$, were supported from the asbestos board, $E$.

The reaction vessel, $N$, was a steel cylinder containing 29 steel trays, $W$, of the form illustrated in figure 2. A total of about 100 grams of $\mathrm{CoF}_{2}$ was placed in the trays, the depth of the powder being about $5 \mathrm{~mm}$ in each tray. The trays were arranged with their flat sides staggered, as indicated in figure 1 , so that the reactant gases flowed over each tray. ${ }^{4}$ Above the trays was a 600 -mesh screen, $X$, to prevent blowing of the cobalt fluoride powder from the reaction vessel.

The reactant gas entered the system through the tube, $C$, and was brought to the temperature of the outer bath before entering the calorimeter. The reactant gas was admitted to the reaction vessel at the bottom, and the product gases, if any, flowed from the top of the reaction vessel through the coiled tube, $O$, in which their temperature was reduced to that of the calorimeter

4 The design of the reaction vessel with trays to contain the cobalt fluoride was suggested by R. D. Fowler, Johns Hopkins University. before entering the tube, $D$, which was immersed in the outer bath.

The electrical energy supplied to the calorimeter in the determination of its energy equivalent was determined from measurements of current and voltage with a potentiometer, in conjunction with a volt box and standard resistor, and measurement of the time of heating, using second signals from a Riefler clock. The temperature of the calorimetric liquid was measured with a 2.5-ohm platinum resistance thermometer, $B$, and a Mueller bridge.

The fluorine, the cobaltous fluoride, and the $\mathrm{C}_{6} \mathrm{H}_{4}\left(\mathrm{CF}_{3}\right)_{2}$ used were obtained by $\mathrm{R}$. Rosen, then of the Kellex Corporation, from E. I. Dupont de Nemours \& Co. No quantitative information concerning the purity of these materials was furnished, but it was stated that the purity was relatively high. The $\mathrm{C}_{6} \mathrm{H}_{4}\left(\mathrm{CF}_{3}\right)_{2}$ was probably a mixture of isomers. The hydrogen used for the measurement of reaction 3 was prepared electrolytically at this Bureau, and was passed over hot copper and through a liquid air trap before entering the reaction vessel.

The drying of the $\mathrm{CoF}_{2}$ powder proved to be difficult. Heating at $350^{\circ} \mathrm{C}$ in vacuum for 28 hours did not remove all the water. For this investigation drying was completed by fluorinating the $\mathrm{CoF}_{2}$ at $250^{\circ} \mathrm{C}$. The same filling of cobalt fluoride was used in all experiments. For use in reaction 1 it was reduced to $\mathrm{CoF}_{2}$ by passing hydrogen through the reaction vessel at $335^{\circ} \mathrm{C}$, and for use in reactions 2 and 3 it was converted to $\mathrm{CoF}_{3}$ by passing fluorine through the reaction vessel at $250^{\circ} \mathrm{C}$.

\section{Details of Procedure}

The energy equivalent of the calorimeter was determined before and after each determination of the heat of a reaction. The correction for thermal leakage, heat of stirring, etc. was calculated for each calorimetric experiment from measurements of rates of change of temperature of the calorimeter in "rating periods" preceding and following the "reaction period."

The amount of reaction was determined from the gain or loss in weight of the reaction vessel. The hot Aroclor corroded the steel vessel, the rate of corrosion increasing with the length of time the Aroclor had been held at the elevated 
temperatures. To reduce the error resulting from corrosion of the reaction vessel, the following steps were taken: (a) The vessel and its connecting tubes were plated with nickel and chromium; (b) the calorimeter was filled with fresh Aroclor for each measurement of the heat of a reaction; (c) the rate of corrosion of the vessel was measured, and a correction for the change in weight due to corrosion was applied to the results. The thermal effect of corrosion at a constant rate would be taken into account in the correction for thermal leakage, etc., mentioned above. The amount of reaction 3 was determined also from the increase in weight of a tube containing Ascarite $(\mathrm{NaOH}$ on asbestos) in which the $\mathrm{HF}$ generated by the reaction was absorbed, followed by a drying agent to absorb water evaporated from the Ascarite. The increase in weight of the Ascarite tube was consistent with the corrected loss in weight of the reaction vessel within 1 percent, which is within the uncertainty of the measurements.

In the measurements of the heat of reaction 2 , the product gases were passed first through a tube containing Ascarite plus drying agent, and thence to a trap immersed in liquid air, and the increases in weight of the trap and of the tube containing Ascarite were determined. It was found that the sum of the losses in weight of the $\mathrm{C}_{6} \mathrm{H}_{4}\left(\mathrm{CF}_{3}\right)_{2}$ container and the reaction vessel was equal (within the accuracy of the measurements) to the gain in weight of the Ascarite plus the weight of the fluorocarbon product condensed in the liquid air trap.

A small flow of helium through the reaction vessel was maintained before and after each "reaction period." While reactions 1 and 3 were proceeding, the flow of helium was stopped, the absolute pressure of the gases in the reaction vessel was held at approximately 3 atmospheres, and the outlet valve was opened slightly to permit a flow of gas from the system. This flow of gas was necessary during reaction 3 for the removal of the product gas, HF, and was found to be necessary during reaction 1 to prevent the impurities in the fluorine from accumulating in the reaction vessel.

During reaction 2 the flow of helium through the reaction vessel was maintained in order to exclude air from the system, and to carry the products of the reaction to the absorbing and con- densing chambers. The $\mathrm{C}_{6} \mathrm{H}_{4}\left(\mathrm{CF}_{3}\right)_{2}$ was vaporized in a metal container immersed in an oil bath at $150^{\circ} \mathrm{C}$. The tube through which the vapor flowed to the calorimeter was electrically heated to prevent condensation. The rate of flow of vapor into the reaction vessel during the two measurements of the heat of reaction 2 was 0.08 and 0.03 gram per minute. In order to favor complete fluorination of $\mathrm{C}_{6} \mathrm{H}_{4}\left(\mathrm{CF}_{3}\right)_{2}$, reaction 2 was stopped before half of the cobalt salt in the reaction vessel had been reduced to the difluoride.

\section{Results}

There are given in table 1 the experimental values of the heats of reactions 1,2 , and 3 . The reduction of the observed value for the heat of reaction 3 from $335^{\circ}$ to $250^{\circ} \mathrm{C}$, made using data on the heat capacities of hydrogen ${ }^{5}$ and hydrogen fluoride, ${ }^{6}$ together with the estimated values 24 cal mole ${ }^{-1} \mathrm{deg}^{-1}$ and $18 \mathrm{cal} \mathrm{mole}^{-1} \mathrm{deg}^{-1}$ for the heat capacities of $\mathrm{CoF}_{3}$ and $\mathrm{CoF}_{2}$, respectively, yielded the value $\Delta H\left(250^{\circ} \mathrm{C}\right)=-73.6 \mathrm{kcal}$. A value $\Delta H\left(250^{\circ} \mathrm{C}\right)=-72.4 \mathrm{kcal}$. was calculated for the heat of reaction 3 by combining our experimental value for the heat of reaction 1 , $\Delta H\left(250^{\circ} \mathrm{C}\right)=-56.1 \mathrm{kcal}$, with the value $\Delta H\left(250^{\circ} \mathrm{C}\right)=-64.3 \mathrm{kcal}$ for the heat of reaction 4. The latter value was derived from the value

TABLE 1. Values of heat of reaction

\begin{tabular}{|c|c|c|c|c|}
\hline Reaction & $\begin{array}{l}\text { Experi- } \\
\text { ment }\end{array}$ & $\begin{array}{c}\text { Heat of } \\
\text { reaction } \\
\Delta H\end{array}$ & $\begin{array}{l}\text { Esti- } \\
\text { mated } \\
\text { prob- } \\
\text { able } \\
\text { error a }\end{array}$ & $\begin{array}{l}\text { Tem- } \\
\text { pera- } \\
\text { ture to } \\
\text { which } \\
\text { reac- } \\
\text { tion is } \\
\text { referred }\end{array}$ \\
\hline \multirow[t]{2}{*}{ (1) $2 \mathrm{CoF}_{2}(\mathrm{c})+\mathrm{F}_{2}(\mathrm{~g})=2 \mathrm{CoF}_{3}(\mathrm{c}) \ldots$} & $\left\{\begin{array}{l}1 \\
2 \ldots \ldots\end{array}\right.$ & $\begin{array}{l}k \sim a l \\
-56.0 \\
-56.2\end{array}$ & kcal & ${ }^{\circ} \mathrm{C}$ \\
\hline & & -56.1 & \pm 2.0 & 250 \\
\hline \multirow{2}{*}{$\begin{array}{l}\text { (2) } \mathrm{C}_{6} \mathrm{H}_{4}\left(\mathrm{CF}_{3}\right)_{2}(\mathrm{~g})+14 \mathrm{CoF}_{3}(\mathrm{c})= \\
\mathrm{C}_{6} \mathrm{~F}_{10}\left(\mathrm{CF}_{3}\right)_{2}(\mathrm{~g})+14 \mathrm{CoF}_{2}(\mathrm{c})+4 \mathrm{HF}(\mathrm{g})_{-}\end{array}$} & $\left\{\begin{array}{l}1 \\
2 \ldots \ldots\end{array}\right.$ & $\begin{array}{l}-406 \\
-412\end{array}$ & & 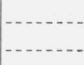 \\
\hline & Mean. & -409 & \pm 20 (?) & 335 \\
\hline (3) $2 \mathrm{CoF}_{3}(\mathrm{c})+\mathrm{H}_{2}(\mathrm{~g})=2 \mathrm{CoF}_{2}(\mathrm{c})+2 \mathrm{HF}$ & $1 \ldots \ldots$ & -74 & \pm 4 & 335 \\
\hline
\end{tabular}

a The estimated probable errors were derived from the agreement of the results of duplicate experiments, together with estimates of the effects of systematic errors. See text for a discussion of the probable error of the heat of reaction 2 .

${ }^{5}$ F. G. Brickwedde, M. Moskow, and J. G. Aston, J. Research NBS 37, 263 (1946).

${ }^{6}$ M. Murphy and J. E. Vance, J. Chem. Phys. 7,806 (1939). 
$\Delta H\left(25^{\circ} \mathrm{C}\right)-=64.2 \mathrm{kcal}^{7}$ for the heat of reaction 4 at $25^{\circ} \mathrm{C}$, together with data on the heat capacities of hydrogen (see footnote 5), fluorine, and hydrogen fluoride (see footnote 6). Our experimental values for the heats of reactions 1 and 3 are therefore consistent with the value (see footnote 7 ) for the heat of reaction 4 to well within the assigned probable errors.

\section{Discussion}

\section{Reaction 1}

As stated in section 1 , the value $\Delta H=-56.1$ kcal, obtained in the present work for the heat of reaction 1 at $250^{\circ} \mathrm{C}$, is in violent disagreement with the value $\Delta H=-159.2 \mathrm{kcal}$ at $260^{\circ} \mathrm{C}$, reported by Jellinek and Koop (see footnote 2 ). The latter value was derived from measurements of the equilibrium concentrations of $\mathrm{HF}$ and $\mathrm{H}_{2}$ in contact with $\mathrm{CoF}_{2}$ and $\mathrm{CoF}_{3}$ over a temperature range from $470^{\circ}$ to $595^{\circ} \mathrm{K}$, together with a value reported in the literature for the heat of formation of $\mathrm{HF}$. In view of the consistency of the values obtained in the present work for the heats of reactions 1 and 3 with the value, $\Delta H$ $\left(250^{\circ} \mathrm{C}\right)=-64.3 \mathrm{kcal}$, for the heat of reaction 4 , it is believed that the value reported by Jellinek and Koop must be seriously in error. It may be noted that the value for the heat of reaction 3 , calculated using the value reported by Jellinek and Koop for reaction 1 and the value (see footnote 7 ) for the heat of reaction 4 , is of opposite sign to the value for reaction 3 found experimentally in the present work.

An experimental value, $\Delta H=-52 \pm 3$ kcal, for the heat of reaction 1 has been reported by Fowler, et al., ${ }^{8}$ who also state that the value reported by Jellinek and Koop leads to values for heats of fluorination of hydrocarbons with $\mathrm{CoF}_{3}$ that are inconsistent as to sign with their laboratory experience.

It is of interest to calculate the equilibrium pressure of $\mathrm{F}_{2}$ over $\mathrm{CoF}_{2}$ and $\mathrm{CoF}_{3}$. An accurate calculation of this pressure is not possible, because the low-temperature heat capacities of $\mathrm{CoF}_{2}$ and $\mathrm{CoF}_{3}$ are not available for a calculation of their

\footnotetext{
${ }^{7}$ Selected Values of Chemical Thermodynamic Properties, National Bureau of Standards, Washington, D. C. Table 9-1.

${ }^{8}$ R. D. Fowler, W. D. Burford, III, J. M. Hamilton, Jr., R. G. Sweet, J. S. Kasper, and I. Litant, Ind. Eng. Chem. 39. 292 (1947).
}

absolute entropies. An approximate calculation, taking

$$
\ln p_{\mathrm{F}_{2}}=\frac{\Delta F^{\circ}}{R T} \cong \frac{\Delta H}{R T}
$$

indicates that $p_{\mathbf{F}_{2}}$ is of the order of $10^{-20}$ atmosphere at $250^{\circ} \mathrm{C}$. In view of this extremely low value for the equilibrium pressure of $\mathrm{F}_{2}$, the reduction of $\mathrm{CoF}_{3}$ in reactions 2 and 3 must involve immediate contact of the gaseous reactant molecules with the $\mathrm{CoF}_{3}$ crystals.

\section{Reaction 2}

The value given in table 1 for the heat of reaction 2 is subject to considerable uncertainty, because of the fact that the exact nature of the reaction between $\mathrm{CoF}_{3}$ and $\mathrm{C}_{6} \mathrm{H}_{4}\left(\mathrm{CF}_{3}\right)_{2}$ in the calorimeter is not known. There is evidence, which indicates that, under the conditions of our experiments, reaction 2 is accompanied by unknown side reactions. Thus, Fowler et al (see footnote 8) report that the reaction of $\mathrm{CoF}_{3}$ with $\mathrm{C}_{6} \mathrm{H}_{4}\left(\mathrm{CF}_{3}\right)_{2}$ under optimum conditions (similar to those in our experiments) gave a crude yield of 97 percent, and a yield of pure $\mathrm{C}_{6} \mathrm{~F}_{10}\left(\mathrm{CF}_{3}\right)_{2}$ of 83 percent. For the same reaction, Benner et al., ${ }^{9}$ report a crude yield of 91 percent, and a recovery of HF of 80 percent of theory.

In our measurements of the heat of reaction 2 , the amount of $\mathrm{C}_{6} \mathrm{H}_{4}\left(\mathrm{CF}_{3}\right)_{2}$ passed into the reaction vessel was found to exceed that chemically equivalent to the loss in weight of the cobalt fluoride. In the first experiment, in which the cobalt fluoride was initially completed fluorinated, the excess of $\mathrm{C}_{6} \mathrm{H}_{4}\left(\mathrm{CF}_{3}\right)_{2}$ was 10 percent, while in the second experiment, after partial reduction of the cobalt fluoride, the excess was 20 percent, although the rate of flow of $\mathrm{C}_{6} \mathrm{H}_{4}\left(\mathrm{CF}_{3}\right)_{2}$ was much lower in the second experiment than in the first.

It is believed that the value given in table 1 for the heat of reaction 2 represents the heat produced per 14 moles of $\mathrm{CoF}_{3}$ reduced in the reaction, or reactions, which actually took place in the calorimetric experiments, within the limits indicated by the assigned probable error. This quantity would be useful in connection with the design of equipment for fluorinating $\mathrm{C}_{6} \mathrm{H}_{4}\left(\mathrm{CF}_{3}\right)_{2}$, and data for this purpose were of primary interest when the work

\footnotetext{
9 R. G. Benner,-A. F. Benning, F. B. Downing, C. F. Irwin, K. C. Johnson, A. L. Linch, H. M. Parmelee, and W. V. Wirth, Ind. Eng. Chem. 39, 329 (1947).
} 
was undertaken. Because of the uncertainty indicated above as to what reactions actually took place in the calorimetric experiments, the true value for the heat of reaction 2 may differ from the value reported in table 1 by considerably more than might be inferred from the assigned probable error.

Benner et al (see footnote 9) reported the value $\Delta H=-460 \mathrm{kcal}$ for the heat of reaction 2. This value was estimated from the observed heattransfer rates, in their fluorination apparatus, during fluorination of $\mathrm{CoF}_{2}$ with gaseous fluorine, and during fluorination of $\mathrm{C}_{6} \mathrm{H}_{4}\left(\mathrm{CF}_{3}\right)_{2}$ by passing it over $\mathrm{CoF}_{3}$. They used a preliminary value, $\Delta H=-58 \mathrm{kcal}$, from the present work for the heat of reaction 1. Using our final value for the heat of reaction 1, their value for reaction 2 becomes $\Delta H=-445 \mathrm{kcal}$. This value is subject to the same uncertainty as ours with respect to the nature of the reaction to which it applies.

WAshington, January 17, 1950. 